\title{
Effects of Hair Dyeing on DNA Damage in Human Lymphocytes
}

\author{
Jin-A CHO ${ }^{1}$, Eunha $\mathrm{OH}^{2}$, Eunil $\mathrm{LeE}^{3}$ and Donggeun $\mathrm{SuL}^{3}$ \\ ${ }^{1}$ Department of Beauty Arts, Seokyeong University, ${ }^{2}$ Graduate Studies of Public Health, Graduate School and \\ ${ }^{3}$ Department of Preventive Medicine, College of Medicine and Institute for Environmental Health, Medical \\ Science Research Center, Korea University, Korea
}

\begin{abstract}
Effects of Hair Dyeing on DNA Damage in Human Lymphocytes: Jin-A CHOA, et al. Department of Beauty Arts, Seokyeong University, Korea-Comet assays were carried out to evaluate DNA damage in human lymphocytes from 20 volunteers before and after hair dyeing. DNA damage in lymphocytes was found to be slightly higher in volunteers after hair dyeing. Tail moments before and after hair dyeing were $1.47 \pm 0.41$ and $1.75 \pm 0.29$ respectively $(p<0.0008)$. DNA damage in lymphocytes showed significant difference with treatment and heating time. The tail moments after $15 \mathrm{~min}$ of treatment time before and after hair dyeing were 1.44 \pm 0.22 and $1.85 \pm 0.36$, respectively $(p=0.0004)$ and the corresponding tail moments in 20 min of heating time before and after were $1.37 \pm 0.15$ and $1.78 \pm 0.34$ $(p=0.0002)$. In conclusion, we found that an acute exposure of hair dyes with heating caused DNA damages in peripheral lymphocytes and that this damage had significant association with treatment and heating time.
\end{abstract}

(J Occup Health 2003; 45: 376-381)

Key words: Comet assay, Lymphocytes, Hair, Dye

According to the National Cancer Institute (NCI) and International Agency for Research on Cancer (IARC), hair dyes that have been widely used are mutagenic and carcinogenic to animals ${ }^{1-4)}$. Hair dyes consist of semi permanent dyes and permanent oxidation type dyes, and these are the most common dyeing systems for coloring hair $^{5}$. The main gradients of permanent oxidant dyes are $\rho$-phenylenediamine, 2,5-diaminotoluene, 2,4diaminoanisole, o-phenylenediamine, and 2-amino-4nitrophenol. $\rho$-Phenylenediamine is the main aromatic

Received May 2, 2003; Accepted Sep 13, 2003

Correspondence to: D. Sul, Department of Preventive Medicine, College of Medicine and Institute for Environmental Health, Medical Science Research Center, Korea University, 5Ka Anamdong Sungbukku, Seoul, 136-701, Korea amine in hair dye formulations and has been reported to increase the tumors in the liver of mice ${ }^{6}$. These gradients were mixed with resorcinol and hydrogen peroxide to form a simple hair dye that contained only one aromatic diamine $^{7)}$.

Hairdressers belong to an occupational group that is commonly affected by occupational skin disease, specifically contact dermatitis, which may be allergic or irritant and less commonly, contact urticaria ${ }^{8)}$. Although epidemiologic studies on occupational exposure to hair dyes have included some reports of a positive association between hair dye and hematopoietic malignancies, overall the evidence linking the personal use of hair dyes to various leukemia and myelodysplastic syndromes subgroups is weak ${ }^{9,10)}$, but it has been reported that there is a statically significant dose-dependent association between hair dyeing and risk of ovarian cancer ${ }^{11}$. Women using permanent hair dyes are not generally considered to have an increased risk of fatal cancer, but women with prolonged used of dark, particularly black, hair dyes may have increased risk of fatal non-Hodgkin's lymphoma and multiple myeloma ${ }^{12)}$.

At 1983, Hofer et al. determined the chromosome aberration after repeated hair dyeing and they found an increase in the chromosome aberration rate with hair dyeing times ${ }^{13)}$, but the levels of sister-chromatid exchange in the peripheral lymphocytes of humans exposed to single applications of proprietary hair dyes showed no such consistent increase. In recent years, single cell gel electrophoresis (SCGE), which is called "the comet assay", has been widely used to detect strand breaks, alkali-labile sites, DNA crosslinking, and incomplete excision repair sites. The technique has been shown to be a very sensitive method and a useful tool to detect genetic damage at the individual cell level and in human biomonitoring ${ }^{14,15)}$.

Sardas et al. found the SCE assay could not detect the mutagenic effects of hair dyes in the lymphocytes of exposed subjects but found that subjects with a history of smoking had slightly more increased SCE than non- 
smokers, but they did not identify differences between subjects exposed to hair dyes and control in the comet assay $^{5)}$.

With this concern, we determined DNA damage in the lymphocytes of volunteers exposed to hair dyes by using the comet assay in this study. Therefore we selected subjects who have no smoking history to eliminate the effects of smoking on DNA damage and found that DNA damage in lymphocytes was treatment and heating time dependent. This is the first report showing that acute exposure to hair dyes causes DNA damage in human lymphocytes by means of the comet assay.

\section{Materials and Methods}

\section{Subjects}

Twenty people were selected from a panel of female volunteers who had responded to an advertisement in three beauty salons located in Seoul. We chose 20 people whose age ranged from 55 to 67 because they were likely to have a long history of hair dyeing. All subjects completed a questionnaire, which included items on smoking, drinking, age, medication, exercise, symptoms and hair dye using a history which detailed the types of dyes, the colors, duration and frequencies. Two separate experiments were carried out on August 13, 2001. The subjects had not dyed their hair for one month before this experiment and all were non-smokers.

According to the manufacturer's instructions, we asked a hairdresser to provide the same hair dyeing treatment to all the subjects, but the treatment times were 5 and 15 min and heating schedules were 10 and 20 min according to amount of hair involved. Natural brown hair dyes commercially obtained from hair salons were used for this study. The ingredients of hair dyes were $\rho$ phenylenediamine, m-amino-phenol, 2,4dichlorodiamino-penoxyethanol, N, N-bis(hydroxyethyl)$\rho$-phenylenediamine sulfate and hydroxyprophyl- bis (Nhydroxyethyl- $\rho$-phenyldamine). The damage found after hair dyeing was not evaluated in this study. Informed consent was obtained from all participants in accordance with the regulations of the institutional review board for human subjects' protection.

\section{Cell preparation and comet assay}

Blood samples, 2-3 $\mathrm{m} l$ of heparinized whole blood, were collected by venipuncture from each human subject before and $6 \mathrm{~h}$ after hair dyeing and delivered immediately to the laboratory. The comet assay was carried out within $3 \mathrm{~h}$ and performed according to Singh with minor modification (Singh et al., 1988). Normal melting point agarose (Ameresco, NMA) and low melting point agarose (Ameresco, LMA) were dissolved in PBS (Gibco BRL) in a microwave oven. In brief, $100 \mu l$ of $1 \%$ NMA applied to fully frosted slides precoated with $50 \mu l$ of $1 \%$ NMA for firm attachment and the slides were allowed to solidify with cover slips in the refrigerator for $5 \mathrm{~min}$. After solidification of the gel, the cover slips were removed and lymphocytes in $50 \mu l$ mixed with $50 \mu l$ of $1 \%$ LMA were added. The cover slips were placed on the layer and the slides were allowed to solidify in the refrigerator for $5 \mathrm{~min}$. After removing the cover slips, $100 \mu \mathrm{l}$ of $0.5 \%$ LMA was applied to the third layer and the slides with cover slips were placed again in the refrigerator for $5 \mathrm{~min}$. The slides were submerged in the lysing solution (2.5 M NaCl, $100 \mathrm{mM}$ EDTA-2Na, $10 \mathrm{mM}$ Tris$\mathrm{HCl}, \mathrm{pH} \mathrm{10;1 \%} \mathrm{Triton} \mathrm{X-100} \mathrm{and} \mathrm{10 \%} \mathrm{DMSO,} \mathrm{pH} 10$ were added fresh) for $1 \mathrm{~h}$. The slides were then placed in unwinding buffer ( $1 \mathrm{mM}$ EDTA and $300 \mathrm{mM} \mathrm{NaOH}$, $\mathrm{pH} 13$ ) for $20 \mathrm{~min}$ and electrophoresis was carried out with the same solution for $20 \mathrm{~min}$ at $25 \mathrm{~V}$ and $300 \mathrm{~mA}$ $(0.8 \mathrm{v} / \mathrm{cm})$. After electrophoresis, the slides were neutralized by washing three times with neutralization buffer (400 mM Tris-HCl, $\mathrm{pH} 7.4$ ) for $5 \mathrm{~min}$ each and were stained with $50 \mu l$ of $10 \mu \mathrm{g} / \mathrm{m} l$ ethidium bromide. The slides were examined with a Komet 4.0 image analysis system (Kinetic Imaging, Liverpool, UK) fitted with an Olympus BX50 fluorescence microscope equipped with an excitation filter of 515-560 nm and a $590 \mathrm{~nm}$ barrier filter. For each treatment group, two slides were prepared and lots of 50 randomly chosen cells (a total of 100 cells) were scored manually. Olive tail moment that was calculated automatically with the Komet 4.0 image analysis system was used, Olive tail moment $\left(=(\text { Tail.mean-Head.mean })^{*}\right.$ Tail\%DNA /100).

\section{Statistical analysis}

Statistical analyses was performed with SAS version 6.12. We used Wilcoxon rank sum test for two group comparison and the Kruskall-Wallis test for multi group comparison. Differences before and after hair dyeing were tested with the Wilcoxon rank sum test. $p$-values were two-tailed.

\section{Results}

1. Comparison of tail moment before hair dye application. Table 1 shows the general characteristics of the subjects. The age of the subjects ranged from 55 to $67 \mathrm{yr}$ and the subjects were divided into two groups by age. The tail moments of the groups, from 55 to $59 \mathrm{yr}$ old and from 60 to $67 \mathrm{yr}$ old, were $1.44 \pm 0.2$ and $1.46 \pm 0.23$, respectively, which was not statistically significant. The differences between the two groups in terms of alcohol consumption, exercise, taking pills and symptoms were not significant (Table 1).

2. Comparison of tail moments before hair dye application by dye color, duration and the frequency of hair dyeing.

Tail moments before hair dyeing were determined by dye color, duration and the frequency of hair dyeing (Table 2). Colors were classified into three groups, light 
Table 1. Comparison of tail moments before hair dye application by the general characteristics of subjects

\begin{tabular}{lcccc}
\hline \multicolumn{2}{l}{ General characteristics } & $\mathrm{N}$ & $\begin{array}{c}\text { Tail Moments } \\
\text { Mean } \pm \text { SD }\end{array}$ & Median (25\% il, 75\%il) \\
\hline Age & $55-59$ & $11(55 \%)$ & $1.439 \pm 0.20$ & $1.42(1.31,1.51)$ \\
(yr old) & $60-67$ & $9(45 \%)$ & $\begin{array}{c}1.458 \pm 0.23 \\
(p=0.879)\end{array}$ & $1.45(1.41,1.51)$ \\
Alcohol & Yes & $3(15 \%)$ & $1.553 \pm 0.29$ & $1.45(1.31,1.51)$ \\
Drinking & No & $17(85 \%)$ & $1.429 \pm 0.19$ & $1.41(1.36,1.89)$ \\
& & & $(p=0.791)$ & \\
Regular & Yes & $13(65 \%)$ & $1.386 \pm 0.17$ & $1.41(1.24,1.50)$ \\
Exercise & No & $7(35 \%)$ & $1.561 \pm 0.23$ & $1.45(1.42,1.89)$ \\
& & & $(p=0.132)$ & \\
Taking pills+ & Yes & $9(45 \%)$ & $1.537 \pm 0.21$ & $1.50(1.41,1.51)$ \\
& No & $11(55 \%)$ & $1.374 \pm 0.17$ & $1.41(1.23,1.47)$ \\
& & & $(p=0.10)$ & \\
Symptoms & Yes & $3(15 \%)$ & $1.543 \pm 0.33$ & $1.51(1.23,1.89)$ \\
& No & $17(85 \%)$ & $1.431 \pm 0.19$ & $1.42(1.31,1.50)$ \\
& & & $(p=0.56)$ & \\
\hline
\end{tabular}

+: The pills were nutrients such as calcium, iron and vitamins. $p$-value by Wilcoxon rank sum test.

Table 2. Comparison of tail moments before hair dye application by dye color, duration and the frequency of hair dyeing

\begin{tabular}{|c|c|c|c|c|}
\hline \multirow{2}{*}{$\begin{array}{l}\text { Hair dyes } \\
\text { Years of use }\end{array}$} & \multirow{2}{*}{$\begin{array}{l}\text { Number of } \\
\text { subjects }\end{array}$} & \multirow{2}{*}{$\begin{array}{c}\text { Tail moment before } \\
\text { hair dyeing }\end{array}$} & \multicolumn{2}{|c|}{ Median (25\%il, 75\%il) } \\
\hline & & & & \\
\hline $0-9$ & 13 & $1.46 \pm 0.19$ & 1.45 & $(1.41,1.51)$ \\
\hline$>10$ & 7 & $\begin{array}{c}1.42 \pm 0.24 \\
(p=0.499)^{\mathrm{a}}\end{array}$ & 1.36 & $(1.23,1.51)$ \\
\hline \multicolumn{5}{|c|}{$\begin{array}{l}\text { Number of times } \\
\text { per year }\end{array}$} \\
\hline 0 & 2 & $1.36 \pm 0.07$ & 1.36 & $(1.31,1.41)$ \\
\hline 6 & 8 & $1.41 \pm 0.18$ & 1.405 & $(1.275,1.555)$ \\
\hline 12 & 7 & $1.38 \pm 0.13$ & 1.42 & $(1.23,1.47)$ \\
\hline 24 & 3 & $\begin{array}{c}1.77 \pm 0.22 \\
(p=0.10)^{\mathrm{b}}\end{array}$ & 1.89 & $(1.51,1.90)$ \\
\hline \multicolumn{5}{|c|}{$\begin{array}{l}\text { Total number of times } \\
\text { over lifetime }\end{array}$} \\
\hline$<48$ & 11 & $1.47 \pm 0.21$ & 1.45 & $(1.31,1.60)$ \\
\hline$\geq 48$ & 9 & $\begin{array}{c}1.42 \pm 0.21 \\
(p=0.62)^{\mathrm{a}}\end{array}$ & 1.42 & $(1.31,1.47)$ \\
\hline \multicolumn{5}{|l|}{ Color } \\
\hline light brown & 13 & $1.43 \pm 0.19$ & 1.45 & $(1.31,1.50)$ \\
\hline dark brown & 3 & $1.55 \pm 0.17$ & 1.60 & $(1.36,1.68)$ \\
\hline black & 2 & $1.53 \pm 0.51$ & 1.53 & $(1.17,1.89)$ \\
\hline None* & 0 & $\begin{array}{c}1.36 \pm 0.07 \\
(p=0.62)^{\mathrm{b}}\end{array}$ & 1.36 & $(1.31,1.41)$ \\
\hline
\end{tabular}

a $p$-value by Wilcoxon rank sum test, ${ }^{b} p$-value by Kruskall-Wallis test. *None: subjects with no history of hair dyeing. 


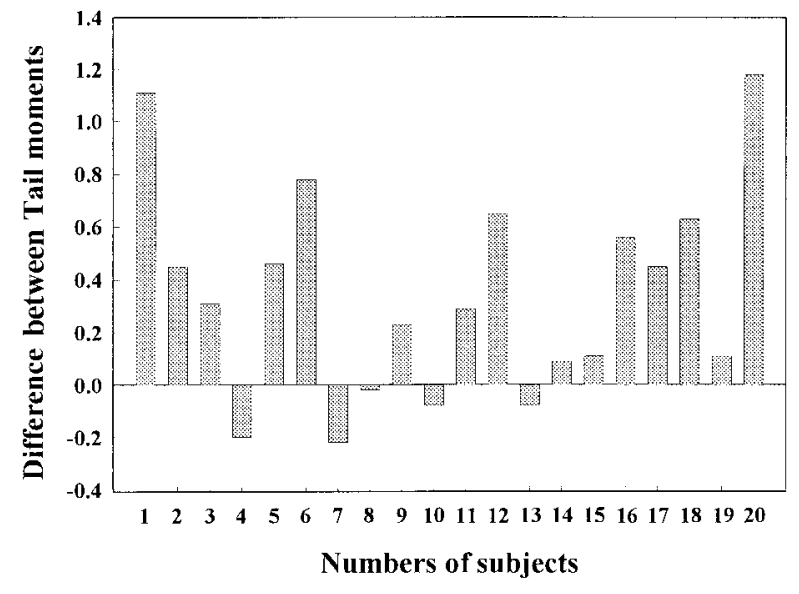

Fig 1. Distribution of Olive tail moments of lymphocytes in subjects before and after hair dyeing.

The mean values for tail moments before and after hair dyeing were $1.45 \pm 0.21$ and $1.79 \pm 0.36$, respectively, and the difference was statistically significant in Wilcoxon rank sum test $(p=0.0008)$.

brown, dark brown and black. The mean values of tail moments in subjects treated with these three colors were $1.43 \pm 0.19,1.54 \pm 0.17$ and $1.53 \pm 0.51$, respectively $(p=0.594)$ (Table 2). Statistically significant difference was not reached. The duration of hair dyeing was divided into less than $5 \mathrm{yr}$ and $10 \mathrm{yr}$. Seven people had $10 \mathrm{yr}$ of experience of hair dyeing. Two people did not have any history of hair dyeing. No significant difference was found between the two groups and their mean tail moments were $1.46 \pm 0.19$ and $1.42 \pm 0.24$, respectively $(p=0.651)$ (Table 2).

The frequency of hair dyeing was divided into three groups, namely, 6, 12 and 24 times per year. The different frequency groups seem to show similar trends in terms of DNA damages, and no significant difference was found between subjects who dyed their hair 6 times per year and those who dyed it 12 times per year. In the case those dyeing their hair 24 times per year, although the subjects showed slightly higher tail moments than the other two groups, i.e., 6 and 12 times per year, evidence of increased DNA damage was weak because of the small number of subjects (Table 2).

\section{Distribution of the difference in tail moments before and after hair dyeing}

Figure 1 shows the different levels of DNA damage in lymphocytes before and after hair dyeing. The tail moment was increased in 15 people among 20 people $6 \mathrm{~h}$ after hair dyeing. This significant difference was determined by comparing before and after hair dyeing. The mean values of tail moments before and after hair dyeing were $1.45 \pm$ 0.21 and $1.79 \pm 0.36$ respectively $(p=0.0012)$
4. Effects of treatment and heating time on DNA damage in lymphocytes

The hair dyeing procedure included dyeing treatment and heating of the hair, which increases the rate of absorption of dyes into the hair. Therefore, DNA damage was determined versus treatment and heating time. Treatment time was divided into $5 \mathrm{~min}$ and $15 \mathrm{~min}$ and heating time into $10 \mathrm{~min}$ and $20 \mathrm{~min}$ (Figs. 2 and 3). At a treatment time of $5 \mathrm{~min}$, the mean values for tail moment before and after hair dyeing were $1.50 \pm 0.10$ and $1.47 \pm$ 0.06 , respectively. DNA damage in 17 subjects with a treatment time of 15 min showed a significant difference before and after treatment. The mean values for tail moment were $1.44 \pm 0.22$ and $1.85 \pm 0.36$, respectively $(p=0.0006)$ (Fig 2).

With a heating time of $10 \mathrm{~min}$, the mean values for tail moment before and after hair dyeing were $1.63 \pm 0.22$ and $1.81 \pm 0.43$, respectively, which was not significant $(p<0.441)$, but DNA damage in 14 subjects with a heating time of 20 min showed a very significant difference. The mean values for tail moment were $1.37 \pm 0.15$ and $1.78 \pm$ 0.34 , respectively ( $p=0.0004)$ (Fig 3$)$.

\section{Discussion}

A few genotoxic studies have been done on hair dyes in humans. In 1981, Kirkland et al. scored the sisterchromatid exchanges in the peripheral lymphocytes of 13 women and 1 man immediately before, and $6 \mathrm{~h}$ and 7 $\mathrm{d}$ after the application of hair dyes by a professional hairdresser under normal conditions. All the hair dyes were mutagenic to Salmonella, but they found that single applications of proprietary hair dyes did not cause a consistent increase in SCE levels ${ }^{16)}$. Hofer et al found an increase in the chromosome aberration rate with time, but observed no difference between the control and exposed subjects ${ }^{13)}$. In recent years, Sardas et al. carried out different tests, i.e., SCE, SCGE and Ames assay, and concluded that the slow penetration and release of currently permitted dyes from the skin into the systemic circulation seems unlikely to have a significant detectable genotoxic effect in terms of occupational exposure ${ }^{5)}$. But in the present study, we used new hair dyeing procedures and included the hair heating stage, which is widely used in hair salons, to increase dye absorption into hair. We used different treatment times for hair dyeing and included a heating stage, and then determined the DNA damage by means of comet assay. The sampling times from subjects before and after hair dyeing were valid in this study.

The general characteristics of the subjects, in terms of age, exercise, drug and symptoms did not gave statistically significant differences in DNA damage. In addition, the results we obtained from the characteristics of the subjects, in terms of the dye colors, duration and frequency of hair dyeing confirm previous findings on 


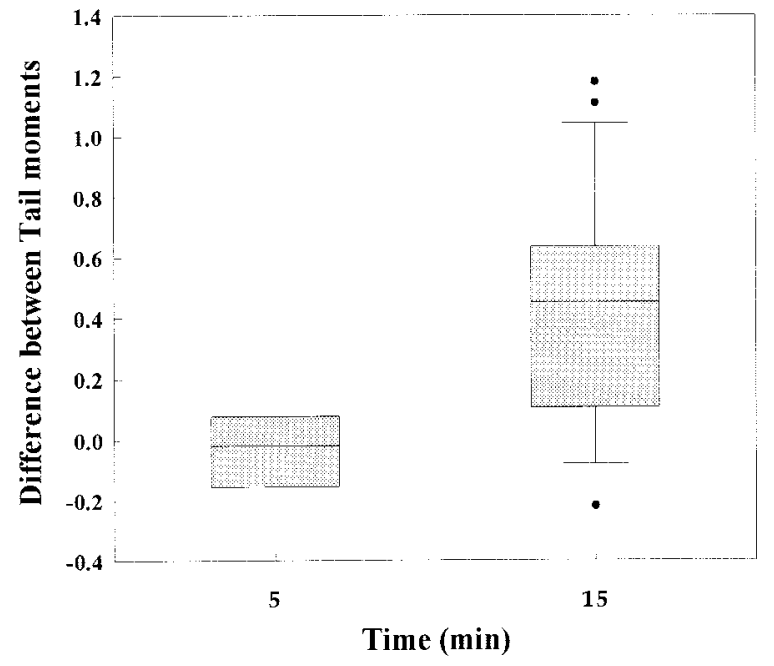

Fig 2. The level of DNA damage in lymphocytes before and after hair dyeing with different treatment times $(5 \mathrm{~min}$ and $15 \mathrm{~min}$ ). At a treatment time of $5 \mathrm{~min}$, the mean values for the tail moments before and after hair dyeing were $1.50 \pm 0.10$ and $1.47 \pm 0.06$, respectively, and at a treatment time of $15 \mathrm{~min}, 1.44 \pm 0.22$ and 1.85 \pm 0.36 , respectively. Only the difference with a treatment time of 15 min was statistically significant in Wilcoxon rank sum test $(p=0.0004)$.

the effects of hair dyes. Although Diem et al. observed that an age-dependent increase in the comet assay tail factor became significant in individuals older than $40 \mathrm{yr}^{17)}$, we did not observe any significant difference between the two age groups, 55-59 and 60-67 yr of age. Sardas et al. found that only smoking caused a slight increase in $\mathrm{SCE}^{5}$. Therefore, for this study we selected subjects who had no smoking history.

Chen et al. reported that two hair dye components, the carcinogenic 4-nitro-2-aminophenol and 5-nitroaminophenol, induced $\mathrm{Cu}(\mathrm{II})$-dependent DNA cleavage frequently at thymine and guanine residues in DNA fragments obtained from the c-Ha-ras-1 protooncogene ${ }^{18)}$.

Many other studies have also looked at percutaneous penetration and the dermal absorption of hair dyes in vivo and in vitro ${ }^{7,19-22)}$. Phenylenediamine and 2,5diaminotoluene, which are essential components of many hair dyes are absorbed through the skin, when the dye is applied to the hair and scalp ${ }^{7}$. Scalp penetration of 7 oxidative and direct hair dyes, which occurs under conditions of hair dye usage was evaluated for both the rhesus monkey and man by using ${ }^{14} \mathrm{C}$ labeled materials and quantifying their absorption via urine assays. In neither case did their absorption exceed $1 \%$ of the applied $\operatorname{dose}^{22)}$. 2-Nitro- $\rho$-phenylenediamine (2NPPD) is also rapidly absorbed and extensively metabolized in human and rat skin and $5-10 \%$ of the 2NPPD that contacts the skin is expected to be absorbed ${ }^{19)}$.

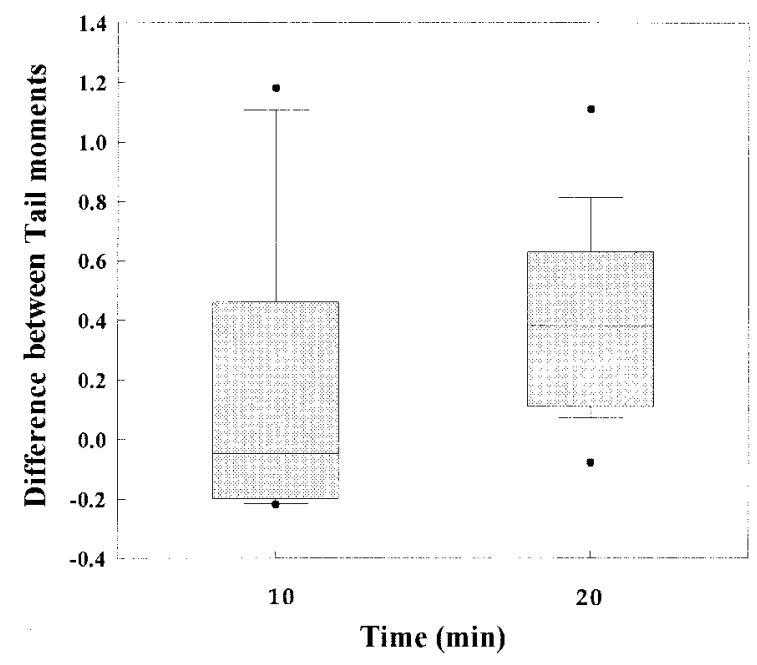

Fig 3. The level of DNA damage in lymphocytes before and after hair dyeing with different heating times (10 min and $20 \mathrm{~min}$ ). In terms of a heating time of $10 \mathrm{~min}$, the mean values of tail moments before and after hair dyeing were $1.63 \pm 0.22$ and $1.81 \pm 0.43$, respectively, and at a heating time of $20 \mathrm{~min}, 1.37 \pm 0.15$ and $1.78 \pm$ 0.34 , respectively. Only the difference with a heating time of $20 \mathrm{~min}$ was statistically significant in Wilcoxon rank sum test $(p=0.0002)$

The present study shows that acute exposure to hair dyes with heating caused DNA damage in peripheral lymphocytes, and that this damage is associated with treatment and is heating time dependent. But it seemed that heating time greatly affected DNA damage in peripheral blood cells because the heating of hair to increase hair dye penetration into hair stimulates the absorption of hair dye into the skin and these dye ingredients caused acute DNA damage in vivo to peripheral lymphocytes. As a limitation of this study, only one time point was examined. If subjects are exposed repeatedly to hair dyes, the more accumulated genetic damage could occur. And if there was genetic damage at more than 6 h, e.q. 24 h, greater DNA damage could be expected. Further studies, involving larger numbers of subjects and various hair dyeing conditions, are required for more precise information about the genotoxicity of hair dyes in humans.

\section{References}

1) F Chen, S Oikawa, Y Hiraku, M Murata, N Yamashita and S Kawanishi: Metal-mediated oxidative DNA damage induced by nitro-2-aminophenols. Cancer Lett 126, 67-74 (1988)

2) K Chung, CA Murdock, SE Stevens Jr, C Li Y Wei, T Huang and MW Chou: Mutagenicity and toxicity studies of $\rho$-phenylenediamine and its derivatives. Toxicol Lett 81, 23-32 (1995)

3) A Correa, A Mohan, L Jackson, H Perry and K 
Helzlsouer: Use of hair dyes, hematopoietic neoplasms, and lymphomas: a literature review. I. Leukemias and myelodysplastic syndromes. Cancer Investigation 18, 366-380 (2000)

4) E Diem, S Ivancsits and HW Rüdiger: Basal levels of DNA strand breaks in human leukocytes determined by comet assay. J Toxicol Environ Health Part A 65, 641-648 (2002)

5) W Diembeck, H Beck, F Benech-Kieffer, P Courtellemont, J Dupuis, W Paye, J Spengler and W Steiling: Test guidelines for the in vitro assessment of dermal absorption and percutaneous penetration of cosmetic ingredients. Food and Chem Toxicol 37, 191205 (1999)

6) H Hofer, N Bornatowicz and E Reindl: Analysis of human chromosomes after repeated hair dyeing. Food and Chem Toxicol 21, 785-789 (1983)

7) IARC, IARC Monographs on the evaluation of the carcinogenic risk of chemicals to man, Vol. 16, some aromatic amines, and related nitro compounds, hair dyes, colouring agents and misscellaneous industrial chemicals. IARC, Lyon, 1978.

8) F Kassie, W Pazefall and S Knasmüler: Single cell gel electrophoresis assay : a new technique for human biomonitoring studies. Mutat Res 463: 13-31 (2000)

9) $M$ Kiese and E Rausher: The absorption of $\rho$ toluenediamine through human skin in hair dyeing. Toxicol Appl Pharmacol 13, 325-331 (1998)

10) DJ Kirkland, JR Honeycombe and SD Lawler: Sisterchromatid exchanges before and after hair dyeing. Mutat Res 90, 279-286 (1981)

11) A Lee and R Nixon: Occupational skin disease in hairdressers Australia. J Dermat 42, 1-6 (2001)

12) P Meller, LE Knudsen and H Wallin: The comet assay, a rapid test in biomonitoring occupational exposure to DNA-damaging agents and effect of confounding factors. Cancer Epidermiol Biom and Prev 9, 10051015 (2000)

13) C Nagata, H Shimizu, K Hirashima, E Kakishita, K
Fujimura, Y Niho, M Karasawa, S Oguma, Y Yoshida and $\mathrm{H}$ Mizoguchi: Hair dye use and occupational exposure to organic solvents as risk factors for myelodysplastic syndrome. Leukemia Res 23, 57-62 (1999)

14) National Cancer Institute, Bioassay of 2,4diaminoanisole sulfate for possible carcinogenicity, carcinogenesis technical report N0. 84. DHEW Publ. NIC-TR-84, Washington, DC. 1978.

15) National Cancer Institute, Bioassay of 2-nitro- $\rho$ phenylenediamine for possible carcinogenicity, carcinogenesis technical report No. 169, DHEW Publ. NCI-TR-169, Washington, DC. 1979.

16) National Cancer Institute, Bioassay of 4-amino-2nitrophenol for possible carcinogenicity, carcinogenesis technical report No. 94, DHEW Publ. NCI-TR-94, Washington, DC. 1979.

17) S Sardas, N Aygun and AE Karakaya: Genotoxicity studies on professional hair colorists exposed to oxidation hair dyes. Mutat Res 394, 153-161 (1997)

18) W Steiling, J Kreutz and H Hofer: Percutaneous penetration/dermal absorption of hair dyes in vitro. Toxicol In Vitro 15, 565-570 (2001)

19) MJ Thun, SF Altekruse, MM Namboodiri, EE Calle, DG Myers and CW Heath Jr: Hair dye use and risk of fatal cancers in U.S. women, J Natl Cancer Inst 86, 210-215 (1994)

20) A Tzonou, A Polychronopoulou, CC Hsieh, A Rebelakos, A Karakatsani and D Trichopoulos: Hair dyes, analgesics, tranquilizers and perineal talc application as risk factors for ovarian cancer. Int $\mathbf{J}$ Cancer 55, 408-410 (1993)

21) LJ Wolfram and HI Maibach: Percutaneous penetration of hair dyes. Arch Dermat Res 277: 235-241 (1985)

22) JJ Yourick, RL Bronaugh: Percutaneous penetration and metabolism of 2-nitro- $\rho$-phenlenediamine in human and fuzzy rat skin. Toxicol Appl Pharm 166, 13-23 (2000) 